\title{
Investigating Aerobic, Anaerobic Combine Technical Trainings' Effects on Performance in Tennis Players ${ }^{i}$
}

\author{
Gürhan Suna*, Mehmet Kumartaşli
}

Faculty of Sport Sciences, Suleyman Demirel University, Isparta, 32200, Turkey

Copyright $(2017$ by authors, all rights reserved. Authors agree that this article remains permanently open access under the terms of the Creative Commons Attribution License 4.0 International License

\begin{abstract}
The aim of this study is to investigate eight-week aerobic, anaerobic combine technical trainings' effects on developments of performance. 21 athletes of tennis proficiency students from Sports Sciences Department were joined to the study voluntarily. Participated in the research athletes' ages' mean was $22,2 \pm 0,3$ year, lengths' mean was $177,3 \pm 1,4 \mathrm{~cm}$, weights' mean was $69,5 \pm 1,4 \mathrm{~kg}$. Trainings were planned as 8 week and 3 days a week, in each unit training 90 minutes. In the research flexibility, vertical jump, standing long jump, right-left hand-grip strength, back and leg strength, anaerobic power, 20 meters shuttle run test, 5 and 10 meters sprint run, 1 maximal strength and ITN technical tests were applied. For analyzing handled data statistically, SPSS programme was used. Paired Samples t Test was applied as statistical process. Comparing before and after training groups' Flexibility, Strength, 5 and $10 \mathrm{~m}$. Sprint run, Anaerobic Power, $20 \mathrm{~m}$. Shuttle Run Test and ITN Technical Test values; there were statistically found to be different in all measurements $(\mathrm{p}<0,05)$. As a result of this study found that, aerobic, anaerobic combine technical trainings affect positively biomotoric, physiologic and technical features.
\end{abstract}

Keywords Aerobic, Anaerobic, Combine Training, Tennis

\section{Introduction}

Today, sport scientists, sport medicine doctors and Today, sport scientists, sport medicine doctors and educators are doing research on various related subjects as a team in order for athletes to be successful and also searching for the ways of having the highest performance with the lowest effort [1]. Research devoted to the improvement of motoric and physiological qualities effective on reaching high performance have been on the increase [2].

As in all branches of sports in modern age, it is important for tennis players to be faster, more skillful and have a distinguished physiological capacity [3].

The human body is composed of muscle, fat and bone of different ratios and concentration. These constituents are effective on performance at different degrees depending on the branch of sport. Effective tests help to reveal that physical structures of an athlete are suitable for a particular sport or not. Therefore, sports scientists have included in their research their body composition and physical profiles besides their physiological profiles [4]. Physiological suitability accompanies certain skills, too and the fact that these parameters are present provides physical competence. The parameters that make up physiological parameters are a healthy and strong heart, strong muscles, body composition, power, elasticity, speed, balance and agility [5].

The duration, frequency and intensity of training must be such that regularly applied training programs can improve and strengthen the physiological functions in the organism. It is fairly hard to think of aerobic and anaerobic energy systems independent of each other during training. However, it is possible to get an idea which system is dominant by examining the intensity and duration of the activity being done. These elements of physiological systems are independent. They are only related to each other during an activity [6].

Anaerobic power is defined as the capability to work without oxygen when the organism can continue working although it cannot get sufficient oxygen $[7 ; 8 ; 9]$.

Tennis, which has millions of fans and players all over the world, is a fast and pleasurable sport branch. When the necessity to play fast and perfect taken into consideration in tennis, it is seen that biomotoric and physiological qualities and technical and tactical parameters are of significance in order to be successful. Since tennis is an individual game which is played fast, aerobic and anaerobic capacities of a player must be high, too.

Maximal oxygen consumption $\left(\mathrm{MaxVO}_{2}\right)$, aerobic capacity etc. are used synonymously with aerobic power, which is defined as the maximal amount of oxygen consumed per minute during maximal exercise $[7 ; 8]$.

$\mathrm{MaxVO}_{2}$ depends on whether $\mathrm{O}_{2}$ is carried by the cardiovascular system to the working muscles and used by 
the cells for energy production here [10].

Efforts which have been made recently in exercise science have created an interest in promoting scientific training programs. The physiological needs of a tennis player in a single game were studied in various studies according to parameters such as oxygen consumption, heart rate and blood lactate concentration. The data obtained from these studies have helped to design scientific training programs prepared according to needs special to sports. On the other hand, technical skills in sports are dominant elements in tennis. Therefore, tennis players spend a great deal of time on improving their tennis skills through technical training. Studies have revealed that individual $\mathrm{MaxVO}_{2}$ values positively affect game performance among top athletes. Studies have shown that special training programs for the improvement of $\mathrm{MaxVO}_{2}$ in certain branches have gained popularity. It was seen that technical capacities in each branch were positively affected [11].

This study seeks to examine the effects of 8 week aerobic-anaerobic combined technical training programs on tennis players.

\section{Materials and Methods}

The Qualities of the Athletes Taking Part in the Study: 21 students from the Faculty of Health Sciences, Suleyman Demirel University participated in the study and an informative meeting was held with the students. The students were assured that the individual data and findings which would be obtained during and after the study would be kept confidential. "an informed consent form" was taken from the athletes who volunteered to participate in the study.

The average age of the athletes who took part in the study was $22,2 \pm 0,3$ years; the average height was found to be $177,3 \pm 1,4 \mathrm{~cm}$ and the average weight was $69,5 \pm 1,4 \mathrm{~kg}$.

Research Materials and Methods: The measurements of the subjects were conducted in the gyms located on the eastern and western parts of the Suleyman Demirel University campus. The measurements were conducted between $13 \mathrm{pm}$ and $15 \mathrm{pm}$.

Measuring Weight: The measurements were conducted with the athletes' barefoot wearing only shorts and t-shirts with platform scales (SECA) with $0,5 \mathrm{~kg}$ precision.

Measuring Height: A SECA trade mark scale was employed to measure height.

Sit and Reach Test (Flexibility Test): The flexibility measurement was done through sit and reach test using a sit and reach box. The test was applied to the athletes after a 5 minute warm-up. The athletes sit on the floor (barefoot) with the soles against the box. Both knees are not bent, held flat against the floor. The athlete reaches forward and pushes the ruler on the box. The reach is held for 2 seconds while the measurement $\mathrm{s}$ recorded. The test is repeated three times and the highest value is recorded in $\mathrm{cm}[12 ; 13 ; 14]$.

One Repetition Maximum Strength Test: The tests were conducted in the condition center at Ataturk Gym.
Following a 15 minute warm up, the athletes were tested with a lat pulley, a shoulder press, triceps curl, biceps curl, calf raise and leg curl condition machines ( all Precor trade mark) and their maximum strength were measured. After the condition machine was adjusted so that the athletes could sit and hold comfortably, a pre-test was done without weight and the maximum estimated weight for the athletes was determined. The maximum weight the athlete could lift was recorded in $\mathrm{kg}$.

Right and Left Hand Grip Strength Test: A Takkei trade mark hand dynamometer was used for the measurement. After a 5 minute warm up, the measurement was done while the athlete was standing with the arm straight and not touching the body at an angle of 45 degree. Right and left hand grip test was repeated three times and the best value was recorded $\mathrm{cm}[12 ; 13 ; 14]$.

Leg Strength Test: A Takkei trade mark leg dynamometer was used for the measurements. After a 5 minute warm up, the athletes place feet on the base of the dynamometer with arms hanging straight down and the torso bend down slightly; then, the athlete grips the bar with the palms facing the body and try to pull the bar vertically with arms and legs straight. The test was repeated three times and the best rate was recorded $\mathrm{cm}[12 ; 13 ; 14]$.

Back Strength Test: A Takkei trade mark back dynamometer was used for the measurements. After a five minute warm up, the subjects placed their feet on the base of the dynamometer with the knees straight. They tried to pull the bar as high as possible, with arms straight down and the torso bent forward slightly $\mathrm{cm}[12 ; 13 ; 14]$.

Vertical Jump Test: After a five minute warm up, a Takkei trade mark jump meter was strapped to the athlete's belly. He was asked to jump vertically in a marked spot. During the tests, the athletes jumped vertically in full force with arms upward and knees bent 90 degree. The test was repeated three times and the best rate was recorded.

Standing Long Jump: After a five minute warm up, the athletes stood behind a line marked on the floor and tried to jump as far as possible with a two feet take off. The farthest line that the athletes were able to jump was recorded in $\mathrm{cm}$. The best rate was recorded after the test was conducted three times.

Five (5) and Ten (10) Meter Sprinting Test: Photoelectric stopwatches were fixed between 0-5 meters and 0-10 meters on the running track. After a 15 minute warm up, the athletes waited at the start. Then, each athlete was individually asked to start and they ran 5 and 10 meters with maximal speed. The time between the start and the finish was recorded with a photoelectric stopwatch. The test was conducted three times and the best rate was recorded.

Wingate Anaerobic Test: A Monark trade mark (model 894 E) bicycle ergometer and a computer mechanism fixed to the bike were employed. A 15 minute active warm up was performed prior to the wingate test. A recovery time of 3 minutes were given to the subjects in order to obtain the best efficiency from the test. The height and weight of the each 
subject was recorded prior to the test. After that, the given weight was placed and the subject began to cycle in full force. Just as he reached the maximum speed, the weight was taken off and the measurement began.

20 Meter Shuttle Run Test: The test was carried out on a 20 meter track in the gym on the western campus of SDU. The start and the finish were marked and the athletes were given signals from a buzzer. The athletes were asked to be within a 2 square meter spot before the start and the finish line. The athletes started the test after a 20 minute warm up. At the end of each shuttle, the athletes were asked to step on the start and the finish lines. While each signal that an athlete caught was recorded as a shuttle, those signals an athlete missed was counted as a failure. When an athlete had three failures in a row, the test was terminated. The estimated $\mathrm{MAXVO}_{2}$ was calculated by using the following formula [15].

The Formula: $Y=31.025+3.238 X-3.248 \mathrm{~A}+0.1536 \mathrm{AX}$ $\left(\mathrm{Y}=\mathrm{MAXVO}_{2}\right.$ ml.kg-1.min-1, $\mathrm{X}=$ =running speed km.h-1, $\mathrm{A}=$ age (year)

Heart Rate Measurements: For the heart rate measurements, a polar watch was used. Heart rate at rest was measured after the athlete lay flat for 5 minutes. Maximal heart rate was measured just after the athlete had a 20 meter shuttle run.

ITN Performance Test: This is an important test which has been developed and applied by the International Tennis Federation in order to determine the initial level of players and how much development they have gained.

ITN Test General Evaluation Rules: The player must be ready having warmed up decently before the test. Before each stage of the test (FH \& BH, volley, service), the player is given 4 trial experience. The player has the right to refuse the ball passed to him by the trainer. He may prefer not to make a stroke. If the player touches the ball, that stroke is counted. When the ball touches the line, the higher score is counted all the time. The rater is the person of authority during the measurements and he has the final say over anything. All the scores were recorded after each shot and at the end of each stage [16].
The Training Program Applied: The trainings were performed 3 days a week for 8 weeks. The frequency of training sessions a day ranged from once to twice. The first training session was between 9-10.30 am and the second one was performed from 16.00 to 17.30 . Each session lasted approximately 90 minutes. The training was performed under the supervision of a trainer. Only drills were performed on single training days. On days with double training sessions, however, while drills were performed in the morning, technical shot exercises were done in the afternoon.

Data Analysis: SPSS 18.0 packaged software was used in this study in order to obtain statistical results. In-group paired t-test was employed in order to determine whether there was a difference in the athletes between pre training and post training. Level of significance was assessed according to $0.001,0.01$ and 0.05 importance levels.

\section{Findings}

Table 1. Physical Information of Training Groups Participating to Research

\begin{tabular}{cccc}
\hline $\begin{array}{c}\text { Parameter } \\
(\mathrm{n}=21)\end{array}$ & Minimum & Maximum & Arithmetic Mean \\
\hline Age (year) & 19 & 26 & $22,2 \pm 1,8$ \\
\hline Length (cm) & 167 & 188 & $177,3 \pm 1,4$ \\
\hline $\begin{array}{c}\text { Body Weight } \\
(\mathrm{kg})\end{array}$ & 56 & 79 & $69,5 \pm 1,4$ \\
\hline
\end{tabular}

Table 2. Comparison of the Pre and Post Measurements of the Flexibility Test of Training Groups Participating to Research

\begin{tabular}{ccccc}
\hline Parameters (n=21) & $\begin{array}{c}\text { Arithmetic Mean } \pm \\
\text { SS }\end{array}$ & $\begin{array}{c}\text { Arithmetic } \\
\text { Mean } \\
\text { Difference }\end{array}$ & t & $\mathrm{p}$ \\
\hline $\begin{array}{c}\text { Flexibility (pretest) } \\
(\mathrm{cm})\end{array}$ & $27,1 \pm 2,0$ & & & \\
$\begin{array}{c}\text { Flexibility (posttest) } \\
(\mathrm{cm})\end{array}$ & $29,6 \pm 2,0$ & & $-13,7$ & $0,001^{* *}$ \\
\hline
\end{tabular}

$* * * \mathrm{p}<0,05, * * \mathrm{p}<0,01, * \mathrm{p}<0,001$ 
Table 3. Comparison of the Pre and Post Measurements of the Strength Test of Training Groups Participating to Research

\begin{tabular}{|c|c|c|c|c|}
\hline Parameters $(\mathrm{n}=21)$ & Arithmetic Mean \pm SS & Arithmetic Mean Difference & $\mathrm{t}$ & $\mathrm{p}$ \\
\hline Biceps curl (pretest) (kg) & $37,3 \pm 4,6$ & \multirow[b]{2}{*}{8,8} & \multirow[b]{2}{*}{$-11,1$} & \multirow[b]{2}{*}{$0,001 * *$} \\
\hline Biceps curl (posttest) (kg) & $46,1 \pm 4,9$ & & & \\
\hline Triceps press (pretest) (kg) & $42,1 \pm 6,8$ & \multirow[b]{2}{*}{7,4} & \multirow[b]{2}{*}{$-15,0$} & \multirow[b]{2}{*}{$0,001 * *$} \\
\hline Triceps press (posttest) $(\mathrm{kg})$ & $49,5 \pm 7,0$ & & & \\
\hline Shoulder press (pretest) kg) & $73,8 \pm 8,2$ & \multirow[b]{2}{*}{7,1} & \multirow[b]{2}{*}{$-14,6$} & \multirow[b]{2}{*}{$0,001 * *$} \\
\hline Shoulder press (posttest) (kg) & $80,9 \pm 6,8$ & & & \\
\hline Lat pulley (pretest) $(\mathrm{kg})$ & $52,6 \pm 7,0$ & \multirow[b]{2}{*}{8,5} & \multirow[b]{2}{*}{$-10,9$} & \multirow[b]{2}{*}{$0,001 * *$} \\
\hline Lat pulley (posttest) (kg) & $61,1 \pm 7,5$ & & & \\
\hline Leg curl (pretest) (kg) & $59,7 \pm 5,5$ & \multirow[b]{2}{*}{8,1} & \multirow[b]{2}{*}{$-15,8$} & \multirow[b]{2}{*}{$0,001 * *$} \\
\hline Leg curl (posttest) (kg) & $67,8 \pm 6,4$ & & & \\
\hline Calf raise (pretest) $(\mathrm{kg})$ & $85,7 \pm 5,0$ & \multirow[b]{2}{*}{13,3} & \multirow[b]{2}{*}{$-9,6$} & \multirow[b]{2}{*}{$0,001 * *$} \\
\hline Calf raise (posttest) (kg) & $99,0 \pm 7,6$ & & & \\
\hline Right Hand Strength (pretest) (kg) & $40,5 \pm 5,4$ & \multirow[b]{2}{*}{5,4} & \multirow[b]{2}{*}{13,1} & \multirow[b]{2}{*}{$0,001 * *$} \\
\hline Right Hand Strength (posttest) (kg) & $45,9 \pm 5,8$ & & & \\
\hline Left Hand Strength (pretest) $(\mathrm{kg})$ & $37,5 \pm 6,1$ & \multirow[b]{2}{*}{2,2} & \multirow[b]{2}{*}{$-5,0$} & \multirow{2}{*}{$0,001 * *$} \\
\hline Left Hand Strength (posttest) (kg) & $39,7 \pm 4,8$ & & & \\
\hline Leg Strength (pretest) (kg) & $98,8 \pm 10,0$ & \multirow[b]{2}{*}{3,8} & \multirow[b]{2}{*}{$-8,3$} & \multirow[b]{2}{*}{$0,001 * *$} \\
\hline Leg Strength (posttest) (kg) & $102,6 \pm 9,8$ & & & \\
\hline Backpack Strength (pretest) (kg) & $103,4 \pm 11,2$ & \multirow[b]{2}{*}{13,6} & \multirow[b]{2}{*}{$-6,5$} & \multirow{2}{*}{$0,001 * *$} \\
\hline Backpack Strength (posttest) (kg) & $117,0 \pm 13,2$ & & & \\
\hline Vertical Jump (pretest) (cm) & $58,4 \pm 5,5$ & \multirow[b]{2}{*}{2,5} & \multirow[b]{2}{*}{$-11,4$} & \multirow[b]{2}{*}{$0,001 * *$} \\
\hline Vertical Jump (posttest) (cm) & $60,9 \pm 4,5$ & & & \\
\hline Standing Long Jump (pretest) $(\mathrm{m} / \mathrm{cm})$ & $2,0 \pm 0,1$ & \multirow[b]{2}{*}{0,2} & & \\
\hline Standing Long Jump (posttest) (m/cm) & $2,2 \pm 0,1$ & & $-5,2$ & $0,001 * *$ \\
\hline
\end{tabular}

$* * * \mathrm{p}<0,05, * * \mathrm{p}<0,01, * \mathrm{p}<0,001$

Table 4. Comparison of the Pre and Post Measurements of $5 \mathrm{~m}$ and $10 \mathrm{~m}$ Sprint Tests of Training Groups Participating to Research

\begin{tabular}{|c|c|c|c|c|}
\hline Parameters $(\mathrm{n}=21)$ & Arithmetic Mean \pm SS & $\begin{array}{c}\text { Arithmetic Mean } \\
\text { Difference }\end{array}$ & $\mathrm{t}$ & $\mathrm{p}$ \\
\hline $5 \mathrm{~m}$ sprint (pretest) $(\mathrm{sec})$ & $1,0 \pm 0,0$ & $-0,1$ & 5,8 & $0,001 * *$ \\
\hline $5 \mathrm{~m}$ sprint (posttest) $(\mathrm{sec})$ & $0,9 \pm 0,0$ & & & \\
\hline $10 \mathrm{~m}$ sprint (pretest) $(\mathrm{sec})$ & $2,1 \pm 0,1$ & & & \\
\hline $10 \mathrm{~m}$ sprint (posttest) (sec) & $2,0 \pm 0,1$ & $-0,1$ & 5,6 & $0,001 * *$ \\
\hline
\end{tabular}

$* * * \mathrm{p}<0,05, * * \mathrm{p}<0,01, * \mathrm{p}<0,001$

Table 5. Comparison of the Pre and Post Measurements of Anaerobic Power Test of Training Groups Participating to Research

\begin{tabular}{|c|c|c|c|c|}
\hline Parameters $(n=21)$ & Arithmetic Mean \pm SS & Arithmetic Mean Difference & $\mathrm{t}$ & $\mathrm{p}$ \\
\hline Bw (pretest) (watt) & $4,6 \pm 0,6$ & & & \\
\hline Bw (posttest) (watt) & $4,5 \pm 0,6$ & $-0,1$ & 3,5 & $0,002 * *$ \\
\hline Pp (pretest) (watt) & $9,6 \pm 1,1$ & & & \\
\hline Pp (posttest) (watt) & $11,5 \pm 1,3$ & 1,9 & 4,8 & $0,001 * *$ \\
\hline Ap (pretest) (watt) & $7,0 \pm 0,9$ & & & \\
\hline Ap (posttest) (watt) & $7,3 \pm 0,7$ & 0,3 & 4,1 & $0,025 * * *$ \\
\hline Mp (pretest) (watt) & $3,2 \pm 0,7$ & & & \\
\hline Mp (posttest) (watt) & $3,9 \pm 0,7$ & 0,7 & $-4,8$ & $0,001 * *$ \\
\hline Pd (pretest) (watt) & $6,7 \pm 1,1$ & & & \\
\hline Pd (posttest) (watt) & $8,4 \pm 1,1$ & 1,7 & $-4,7$ & $0,001 * *$ \\
\hline
\end{tabular}

$* * * \mathrm{p}<0,05, * * \mathrm{p}<0,01, * \mathrm{p}<0,001$ 
Table 6. Comparison of the Pre and Post Measurements of $20 \mathrm{~m}$ Shuttle Run Test of Training Groups Participating to Research

\begin{tabular}{|c|c|c|c|c|}
\hline Parameters $(\mathrm{n}=21)$ & Arithmetic Mean \pm SS & $\begin{array}{l}\text { Arithmetic Mean } \\
\text { Difference }\end{array}$ & $\mathrm{t}$ & $P$ \\
\hline Resting Heart Rate (pretest) (beat/min) & $77,5 \pm 4,6$ & \multirow{2}{*}{$-6,7$} & \multirow{2}{*}{16,8} & \multirow{2}{*}{$0,001 * *$} \\
\hline Resting heart rate (posttest) (beat/min) & $70,8 \pm 4,5$ & & & \\
\hline Maximum Heart Rate (pretest) (beat/min) & $180,4 \pm 10,3$ & \multirow{2}{*}{$-7,9$} & \multirow{2}{*}{10,2} & \multirow{2}{*}{$0,001 * *$} \\
\hline Maximum Heart Rate (posttest) (beat/min) & $172,5 \pm 8,9$ & & & \\
\hline $\mathrm{MaxVO}_{2}$ (pretest) $(\mathrm{ml} / \mathrm{kg} / \mathrm{dk})$ & $41,8 \pm 3,8$ & \multirow{2}{*}{2,2} & \multirow{2}{*}{$-6,2$} & \multirow{2}{*}{$0,001^{* *}$} \\
\hline $\mathrm{MaxVO}_{2}$ (posttest) $(\mathrm{ml} / \mathrm{kg} / \mathrm{dk})$ & $44,0 \pm 4,0$ & & & \\
\hline Shuttle Run Distance Traveled (pretest) (m) & $1437,8 \pm 146,3$ & \multirow{2}{*}{126,9} & \multirow{2}{*}{$-11,5$} & \multirow{2}{*}{$0,001 * *$} \\
\hline Shuttle Run Distance Traveled (posttest) (m) & $1564,7 \pm 154,9$ & & & \\
\hline Shuttle Run Test Over Time (pretest) (dk) & $8,5 \pm 0,7$ & \multirow{2}{*}{0,7} & \multirow{2}{*}{$-10,4$} & \multirow{2}{*}{$0,001 * *$} \\
\hline Shuttle Run Test Over Time (posttest) (dk) & $9,2 \pm 0,9$ & & & \\
\hline Shuttle Run Test Speed Level (pretest) (km) & $12,5 \pm .3$ & \multirow{2}{*}{0,2} & \multirow{2}{*}{$-3,9$} & \multirow{2}{*}{$0,001 * *$} \\
\hline Shuttle Run Test Speed Level (posttest) (km) & $12,7 \pm .4$ & & & \\
\hline
\end{tabular}

$* * * \mathrm{p}<0,05, * * \mathrm{p}<0,01, * \mathrm{p}<0,001$

Table 7. Comparison of the Pre and Post Measurements of ITN Technic Test of Training Groups Participating to Research

\begin{tabular}{ccccc}
\hline Parameters ( $\mathrm{n}=21)$ & Arithmetic Mean \pm SS & Arithmetic Mean Difference & $\mathrm{t}$ & $\mathrm{p}$ \\
\hline ITN (pretest) (point) & $124,3 \pm 22,6$ & & & \\
\cline { 1 - 1 } ITN (posttest) (point) & $193,6 \pm 20,5$ & 69,3 & $-27,6$ & $0,001^{* *}$ \\
\hline
\end{tabular}

$* * * \mathrm{p}<0,05,{ }^{* *} \mathrm{p}<0,01,{ }^{*} \mathrm{p}<0,001$

\section{Discussion}

This study seeks to investigate the effects of an 8 week aerobic-anaerobic combined technical training program on tennis players' performance. A total of 21 tennis students from the department of Sports Sciences, Faculty of Health Sciences, Suleyman Demirel University participated in the study. The students voluntarily took part in the study.

The average age of the athletes who participated in the study was $22.2 \pm 0.3$ years; average height $177.3 \pm 1.4 \mathrm{~cm}$ and average weight was found $69.5 \pm 1.4 \mathrm{~kg}$.

Flexibility means being able to do movements in harmony together with various parts of the muscular system [17]. Flexibility, which means the free movement of joints within the normal limits of action, is known to affect an athlete's performance. Not learning enough number of techniques, a higher risk of injury, insufficient quality of movements, a slow development of performance, worsening of technique do occur among athletes who are not flexible enough [18].

The average of the flexibility measurements was found to be $27.1 \pm 2.0 \mathrm{~cm}$ before the training and $29.6 \pm 2.0 \mathrm{~cm}$ after the training. This shows that the combined trainings significantly improved flexibility. The flexibility value that we found in the study may be considered positive according to the given values in the literature.

In an 8 week strength training program given by Söyleyici (2011) for teaching tennis techniques, the pre training flexibility values of the control group $31.2 \pm 4.5 \mathrm{~cm}$ and post training flexibility value was found to be $30.8 \pm 4.2 \mathrm{~cm}$ [19]. Gelen et al (2006), in a study in which they investigated the physical fitness of tennis players from the 1 st and 2 nd division, determined the flexibility values as $20.6 \pm 2.39 \mathrm{~cm}$ [20]. The difference between our findings and the ones determined in this study may be due to the age differences and different physical qualities on the part of the participants or training programs.

Strength is of great importance in tennis today for a player to show superior performance. In tennis, the lower extremity strength provides catching the ball in the shortest time possible and taking the right position and the upper extremity strength is important for stronger and faster shots [21].

Pre-training strength values: biceps curl $37.3 \pm 4.6 \mathrm{~kg}$, triceps press $42.1 \pm 6.8 \mathrm{~kg}$., shoulder press $73.8 \pm 8.2 \mathrm{~kg}$., lat pulley $52.6 \pm 7.0 \mathrm{~kg}$., leg curl $59.7 \pm 5.5 \mathrm{~kg}$., calf raise $85.7 \pm 5.0$ $\mathrm{kg}$., right hand grip strength $40.5 \pm 5.4 \mathrm{~kg}$., left hand grip strength $37.5 \pm 6.1 \mathrm{~kg}$., leg strength $98.8 \pm 10.0 \mathrm{~kg}$., back strength $103.4 \pm 11.2 \mathrm{~kg}$., vertical jumping $58.4 \pm 5.5 \mathrm{~cm}$, standing long jump $2.00 \pm 0.1 \mathrm{~cm}$. At the end of the 8 week training, the following values were determined: biceps curl $46.14 .9 \mathrm{~kg}$., triceps press $49.5 \pm 7.0 \mathrm{~kg}$., shoulder press $80.9 \pm 6.8 \mathrm{~kg}$., lat pulley $61.1 \pm 7.5 \mathrm{~kg}$., leg curl $67.8 \pm 6.4$., calf raise $99.0 \pm 7.6 \mathrm{~kg}$., right hand grip strength $45.9 \pm 5.8 \mathrm{~kg}$., left hand grip strength $39.7 \pm 4.8 \mathrm{~kg}$., leg strength $102.6 \pm 9.8 \mathrm{~kg}$., back strength $117.0 \pm 13.2 \mathrm{~kg}$., vertical jump $60.9 \pm 4.5 \mathrm{~cm}$., standing long jump $2.2 \pm 01 \mathrm{~cm}$. There was a significant difference between pre training average strength values and post training average strength values $(p<0.05)$. We can conclude that the improvement in the strength parameters was due to the strength drills in the combined training. We 
assume that the improvement in the strength values will positively contribute to making stronger technical shots.

Gelen et al. did a study on a group of first and second division tennis players in 2006. For the first division tennis players, they found the dominant hand grip strength values as $46.2 \pm 3.4 \mathrm{~kg}$ and non-dominant hand grip strength values as $39.6 \pm 3.4 \mathrm{~kg}$; for the second division tennis players, the dominant hand grip strength value was $46.04 .9 \mathrm{~kg}$ while the non-dominant hand grip strength value was $37.7 \pm 4.9 \mathrm{~kg}$ [20]. Müler et al (2000), in a study they conducted on elite tennis players, found the average isometric strength value 53.0 5 5.9 $\mathrm{kg}$ [22]. Söyleyici in a study he conducted in 2011 found the pre training leg strength value $104.114 .3 \mathrm{~kg}$ and post training leg strength value $107.6 \pm 14.6 \mathrm{~kg}$ for the trained group [19].

Özcan found pre training leg strength value as $100.2 \pm 6.9$ $\mathrm{kg}$; post training leg strength value as $100.9 \pm 7.0 \mathrm{~kg}$ for the induction group [23]. In the literature for male tennis players, dominant hand isometric strength values are expected to be 51-60 kg, non-dominant hand isometric strength values are expected to be $31-36 \mathrm{~kg}$; leg strength values are expected to be $214-240 \mathrm{~kg}$ and back strength values $177-208 \mathrm{~kg}$ [24].

We can conclude in the light of these results that leg and back strength values of the athletes in our study have reached the expected level in the literature and thus will contribute to performance improvement.

Aslan et al. determined vertical jump values as $61.6 \pm 6.8$ $\mathrm{cm}$ in a study conducted in 2011[25]. Soykan determined vertical jump value as $67.2 \pm 6.7 \mathrm{~cm}$ in a study he did on national team karate players in 2003[26]. Saka et al found standing long jump values $205.1 \pm 18.7 \mathrm{~cm}$ in a study they carried out in 2008 [27]. The findings in the studies above are similar to the vertical jump and standing long jump values in our study. We may say that there will be an improvement in vertical jump and standing long jump values thanks to the training program.

In tennis, speed is an important factor for reaching the ball on time [21]. In a study done in conjunction with this, pre training and post training average 5 meter sprint rates were determined $1.0 \pm 0.0 \mathrm{sec}$ and $0.9 \pm 0.0 \mathrm{sec}$ respectively; as for the 10 meter sprint, pre training and post training average rates were found $2.1 \pm 0.1 \mathrm{sec}$ and $2.0 \pm 0.1 \mathrm{sec}$ respectively. There was a significant difference between the pre training and post training sprints of 5 and 10 meters $(p<0.05)$. It is possible to conclude that such an improvement in sprint rates will contribute positively to reaching the ball in the shortest time possible and taking the right position.

In a study in which the effect of an 8 week strength training on the motoric capabilities of male tennis players whose ages range from 12 to 14 , while in the pre test measurement 5 and 10 meters sprint rates were found to be $1.05 \pm 0.03 \mathrm{sec}$ and $1.87 \pm 0.06 \mathrm{sec}$ respectively, post training rates were $0.99 \pm 0.06 \mathrm{sec}$ and $1.85 \pm 0.05 \mathrm{sec}$. The results suggest that sprint performances of the athletes may be enhanced depending on the strength drills. Since there is not enough information on 5 and 10 meter sprints in the literature, our study is thought to be taken as reference in future studies.
Tennis is a sport branch in which anaerobic energy is intensively used. The fact that tennis players' heart rates reach maximal levels during a 2.5-3 hour game when all shots must be done with speed and strength show how important anaerobic strength is on tennis players.

The measured values of the athletes before anaerobic strength training: $\mathrm{Bw} 4.6 \pm 0.6$ watt, $\mathrm{Pp} 9.6 \pm 1.1$ watt, Ap $7.0 \pm 0.9$ watt, Mp $3.2 \pm 0.7$ watt, Pd $6.7 \pm 1.1$ watt; after anaerobic strength training: Bw $4.5 \pm 0.6$ watt, Pp $11.5 \pm 1.3$ watt, Ap $7.3 \pm 0.7$ watt, Mp $3.9 \pm 0.7$ watt, $\mathrm{Pd} 8.4 \pm 1.1$ watt. It was seen that there was a significant difference between the pre training and post training anaerobic strength values $(p<0.05)$. This significant increase in anaerobic strength is closely related to the training program applied.

Özcan, in a study he conducted in 2011, divided the athletes into two groups and tried to teach tennis to one group through induction and the other through deduction. He applied wingate anaerobic strength test, which we also applied in our study, in order to determine the athletes' anaerobic development. There was not any significant development between pre training and post training wingate anaerobic strength values for both the induction and the deduction group [23]. The primary reason why the findings in this study and those in ours are not similar may be due to the different training programs.

In our study, for the 20 meter shuttle run, the following values were found: before the training heart rate volume at rest: $77.5 \pm 4.6 \mathrm{rate} / \mathrm{min}$., maximum heart rate volume $180.4 \pm 10.3$ beat $/ \mathrm{min}$., MaxVO $241.8 \pm 3.8 \mathrm{ml} / \mathrm{kg} / \mathrm{min}$., the distance covered: $1437.8 \pm 146.3 \mathrm{~m}$., shuttle run test finish time $8.5 \pm 0.7 \mathrm{~min}$, shuttle run test speed level $12.5 \pm 0.3 \mathrm{~km}$., after training at rest: heart rate volume $70.8 \pm 4.5$ beat $/ \mathrm{min}$., maximum heart rate volume $172.5 \pm 8.9$ beat $/ \mathrm{min}$., $\mathrm{MaxVO}_{2}$ $44.0 \pm 4.0 \mathrm{ml} / \mathrm{kg} / \mathrm{min}$., the distance covered $1564.7 \pm 154.9 \mathrm{~m}$., shuttle run test finish time $9.2 \pm 0.9 \mathrm{~min}$, shuttle run test speed level $12.7 \pm 0.4 \mathrm{~km}$. There were significant differences between all aerobic strength values before and after training $(p<0.05)$.

It is a practical method to measure heart rate volume during a game of tennis in order to determine the intensity of the game. The average heart rate was found to be $144.6 \pm 13.2$ beat/min. for elite tennis players in $85 \mathrm{~min}$. game of tennis. The fact that heart rate volume before the game has significantly increased during the game may be due to the intense and intermittent nature of the game [28].

A total of 135 games of 50 minutes ( 10 test games) were held between 20 elite Austrian tennis players who were 26 years old and whose heart rate volume were $193 \pm 9$ in order to determine the physiological appearance. At mmol lactic acid level, heart rate volume was found to be $172 \pm 10$ and the average heart rate volume was found to be 151 during the total 270 games [29].

In studies, it was determined that athletes whose ages ranged from 20 to 30 had heart rate volume ranging from 140 to 160 and this rate was 60 to 70 per cent of $\mathrm{MaxVO}_{2}$. It may be seen that heart rate volume reaches 190 to 200 beat $/ \mathrm{min}$ during long rallies and fast games [30]. 
Davey et al. did a study on 5 male 21 year old tennis players in 2003 during a simulated tennis exercise, maximum heart rate volume was found to be $193 \pm 5$, and $\mathrm{MaxVO}_{2}$ was $58.0 \pm 1.7 \mathrm{ml} / \mathrm{kg} / \mathrm{min}$. and heart rate volume interval 140 to 157 , which corresponds to 73 to 81 per cent of maximum heart rate volume. The fact that the rate reached such high levels may be due to the high intensity episodes in the game and to the reactions stemming from psychological strain [31].

Maximal Oxygen consumption $\left(\mathrm{MaxVO}_{2}\right)$ is specified as the biggest determinant of aerobic capacity and cardiorespiratory. Kovacs $\mathrm{MaxVO}_{2}$ values in the compilation of their research they found in the literature of 44 to $69 \mathrm{ml} / \mathrm{kg} / \mathrm{min}$., the majority of research in $50 \mathrm{~m} / \mathrm{kg} /$ min is that they have expressed [28].

It was determined that aggressive players (those who play close to the net) had a lower $\mathrm{MaxVO}_{2}$ compared to baseline players. The previous studies suggest that elite tennis players' $\mathrm{MaxVO}_{2}$ level must be around $50 \mathrm{ml} / \mathrm{kg} / \mathrm{dk}$ [28].

Girard et al conducted a study on 916 year old tennis players in 2006. In the study, they conducted 8 training sessions a week and found $\mathrm{MaxVO}_{2}$ levels $57.4 \pm 6.4$ and $58.2 \pm 6.5 \mathrm{ml} / \mathrm{kg} / \mathrm{min}$. after performing maximal tests on a treadmill with 4 day intervals and two different protocols [32].

Hughes et al. found $\mathrm{MaxVO}_{2}$ level as $51.5 \mathrm{ml} / \mathrm{kg} / \mathrm{min}$. in a study they did on 13 elite badminton players. Reilly et al. determined $\mathrm{MaxVO}_{2}$ level as $58.8 \mathrm{ml} / \mathrm{kg} / \mathrm{min}$. in a study they did on 13 male squash players. Segun et al. conducted a study on 6 male elite table tennis players and determined $\mathrm{MaxVO}_{2}$ level as $47 \mathrm{ml} / \mathrm{kg} / \mathrm{min}$ [33]

In various studies done in a laboratory setting, Reilly and Palmer determined $\mathrm{MaxVO}_{2}$ level as 53.2 \pm 7.3 for 8 elite tennis player; Vodak et al. in a study they conducted on 25 male elite tennis players found $\mathrm{MaxVO}_{2}$ level as 50.2 \pm 5.7 ; Bergeron et al. found $58.5 \pm 9.4$ for national team male tennis players; Smekal et al. determined $57.3 \pm 5.1$ for 20 international tennis players [34].

The $\mathrm{MaxVO}_{2}$ values that we found in the aerobic strength test in our study were lower compared to those in the literature, which is thought to have stemmed from the differences between the field and laboratory tests. However, the $\mathrm{MaxVO}_{2}$ values that we determined in our study are of the levels that are suitable for elite athletes.

Tennis is a sport branch in which unexpected movements and incidents occur. These unexpected phenomena, the length of the number, stroke choice, the strategy, duration of the game, the weather and the complex physiological appearance of the opponent do affect the game. In tennis, many physiological, technique and tactical variables, which are important for designing and applying training programs, must be understood in depth. In the light of this information, by structuring both court condition and court technique training programs greater performance can be achieved [11].

ITN test was used in order to determine the tennis technique values of the athletes in our study. In our study, prior to the test, ITN technique value found was $124.3 \pm 22.6$ points and after the test, ITN technique value was determined as $193.6 \pm 20.5$ points. Significant differences were found between pre test and after ITN technique test measurements $(p<0.05)$. Therefore, we can say that the combined training model that we applied has improved both techniques and performance properties of the athletes.

ITN pre test scores and after test scores of the athletes were found $75 \pm 0.0$ and $148.9 \pm 18.2$ respectively in a study in which strength and technique drills were done together. At the end of the study, there was a significant increase in the ITN scores of the athletes [19]. The findings in this study and those in ours are similar.

In order to determine the athletes' development, Özcan employed an ITN test in 2011, which we also employed in our study. Significant developments were determined between ITN pre test and post test scores for both induction and deduction method groups [23].

Although the values are not similar to those in the literature, it is possible to conclude that there is a similarity between performance developments. Because the studies done according to the ITN scoring system are few in number, we think that this study will be a reference for the future studies to be done in this field.

\section{Conclusions}

The data obtained show that the 8 week combined training program applied has significantly improved techniques, aerobic and anaerobic capacities and biomotoric qualities, which, by extension, enhanced overall performance. 5 tennis players, who constitute SDU male tennis team and who participated in our study, were promoted to the upper division having become the first in their group, which proves the positive developments thanks to our combined training program.

At the end of our study, we think that the athletes and trainers who have applied combined technique aerobic and anaerobic training programs will make great contributions to the field.

Tennis sports; for implement and the perception of the skills with aerobic, anaerobic capacity, strength, force quickly, and the flexibility, the motion also requires that the integrity specific to tennis. With built in training programs for longer periods on this information, we think it would be useful in terms of gaining success and to reach the world standards the performances of Turkish tennis players.

\section{REFERENCES}

[1] Kasap H. (1990) Sports Talent and in Our Country The Situation, The Journal of Sports Sciences, Year 1, Issue 3-4, S 36-38.

[2] Sevim Y. (1997) Training Information, Tubitak Besyo Publications, p: 74-79, Ankara. 
[3] Ersöz, G., Koz M., Sunay, H., Gündüz, N. (1996) Changes in Physical Fitness Level Parameters Pre-Season, Mid-Season and Season End of the Men Volleyball Player. Journal of Gazi University School of Physical Education and Sports Sciences, Volume: L, No. 4, p: 1-7, Ankara.

[4] Kuter, M., Öztürk, F. (1992) Physical and Physiological Profile of the Men's Basketball Team. Sport Science National Conference Proceedings. Hacettepe University, School of Sports Science and Technology Press, p: 221- 226, Ankara.

[5] Ağaoğlu, S.A. (1989) Analysıs of Varıous Physiological Characteristics of Physical Education and Sport Department Students At Metu, Master's Thesis, Ankara.

[6] Şenel, Ö. (1995) Effects on Some Physiological Parameters 13-16 Age Group Male Students of Aerobic and Anaerobic Training Program. Gazi University Institute of Health Science in Physical Education and Sports Department, Ankara.

[7] Ateşoğlu, U. (1995) Evaluation of Physical and Physiological Profile of Elite Female Handballer. Institute of Health Sciences, Department of Physical Education and Sports, Master Thesis, Ankara.

[8] Baker, J., Rambsbottom, R., Hazeldine, R. (1993) Maksimal Shuttle Running Over $40 \mathrm{~m}$ as a Measure of Anaerobic Performance, British Journal of Sports Medicine, 27 (4) : p:228- 232.

[9] Malıne, R.M. (1994) Phsycal Activity and Training Effects on Stature and the Adolescent Frowth Spurt. Medicine and Science in Sports and Exercise, 26(6): 759-766.

[10] Hartung, G.H. (1995) Estimation of Aerobic Capacity From Submaksimal Cycle Ergometry in Women, Medicine and Science in Sports and Exercise, 27 (3) : 299-168.

[11] Işıı, M. (2009) Effects To $\mathrm{Vo}_{2} \max$ and Technical Performance Level of Specific Training Applied to the Elite Tennis Players. Movement and Training Sciences Department Programme. Ph.D.

[12] Özer, K. (2001) Physical Fitness, Nobel Publications, p: 61-194, Ankara.

[13] Tamer, K. (2000) Measurement and Evaluation of Physical-Physiological Performance in Sport. Bağırgan Publishing, p: 130-131, 139-140.

[14] Zorba, E. (1993) Physical Fitness and Sports for Everyone. GSGM Publications, No: 149, p: 96-159, 324-443.

[15] Leger, L. A., Mercier, D., Gadoury, C. Lambert, J. (1988) The Multistage 20 Metre Shuttle Run Test For Aerobic Fitness, Journal of Sports Sciences, 6:2, $93-101$.

[16] http://www.1tftennis.com/media/113844/113844.Pdf (date of access:12.02.2013)

[17] Mengütay, S. (1997) Development of Movement and Sports Preschool and Primary, Istanbul.

[18] Alter M. (1996) Science of Flexibility, Human Kinetics Pub, p: $165-170$.

[19] Söyleyici S.Z. (2011) Investigation of The Effect on Biomotoric and Technical Developments of 8 -Week
Intensive Force and Technical Training Program in Tennis Technical Education. Suleyman Demirel University, Institute of Health Sciences, Department of Sport Science, M.Sc., Isparta.

[20] Gelen, E.,Saygın, Ö.,Karahan, M., Karacabey, K. (2006) Comparison of Physical Fitness Characteristics of 1 st and 2nd League Tennis Player. FU Journal of Health Science, 20 (2), 119-127.

[21] Chu, D.A. (1995) Power Tenis Training., Human Kinetics Champaign, p:7-15, 33-45.

[22] Müler, E., Benko, U., Raschner, C., Schwameder, H. (2000) Specific Fitness Training and Testing in Competitive Sports., Med. Sci. Sports Exercise. 32 (1): 216-220.

[23] Özcan S. (2011) Investigation of The Effect on Technical, Biomotoric and Physiological Properties Motoric of Two Different Training Methods in Basic Tennis Technical Education. Suleyman Demirel University Institute of Health Sciences, Department of Sport Science, M.Sc., Isparta.

[24] Gullikson, T. (2003) Tennis on Physical Fitness Test. Sports Research Journal, Volume 7, Number 1, S.135-156.

[25] Aslan, C.S, Koç, H., Köklü, Y. (2011) Effects the Over of Strength, Anaerobic Power and Flexibility in Athletes and Sedentary Men of 18-30 Age Period. Journal of Sports Sciences, 20 (1), p:.48-53.

[26] Soykan, A. (2003) Investigation of Physical and Motoric Profile of Elite Karate Athletes. Marmara University, Master Thesis, Istanbul.

[27] Saka, T., Yıldızy., Tekbaș, Ö.F., Aydın, T. (2008) Impact on Physical Capacity the of Young Adult Male of Sports School Education. Journal of Physical Education and Sports Sciences, Volume 2, Issue 1.

[28] Kovacs, M.S. (2007) Applied Physiology of Tennis Performance. Br J. Sports Med. 40: 381-6.

[29] Smekal, G., Polen, R., Van Duvillard, S.P., Baron, R., Tschan, H., Bachl, N. (2000) Comparison of Laboratory and "On-Court" Endurance Testing in Tennis. Int J Sports Med. May, 21(4):242-9.

[30] Konig, D., Huonker, M., Schmid, A., Halle, M., Berg, A., Keul, J. (2001) Cardiovascular, Metabolic and Hormonal Parameters in Professional Tennis Players. Med.Sci. Sports Exerc: 33 ; 654-658.

[31] Davey, P.R., Thorpe, R.D., Williams, C. (2003) Simulated Tennis Match Play in a Controlled Environment. Journal of Sports Sciences, 21; p: 459-67.

[32] Girard, O., Chevalier, R., Levegue, F., Miczllef, P.J., Millet, P.G. (2006), Specific Incremental Field Test for Aerobic Fitness in Tennis. Br J Sports Med.; 40: 791- 796.

[33] Lees, A. (2003) Science and the Major Racket Sports: A Review. Journal of Sports Sciences, 21, 707-732.

[34] Fernandez, J., Mendez, A. Villanueva, Pluim Bm. (2006) Intensity of Tennis Match Play. Br J Sports Me, 40: 387-391.

\footnotetext{
${ }^{\mathrm{i}}$ This study is made from a graduate thesis.
} 